\title{
Low Cycle Fatigue Behaviour of Nitrided Layer of 42CrMo4 Steel
}

\author{
Mohamed Ali Terres, Rafik Bechouel, Salem Ben Mohamed \\ Laboratory Mechanics, Materials and Processes (LMMP) ENSIT, University of Tunis, Tunis, Tunisia \\ Email address: \\ Mohamedali_terres@yahoo.fr (M. A. Terres) \\ To cite this article: \\ Mohamed Ali Terres, Rafik Bechouel, Salem Ben Mohamed. Low Cycle Fatigue Behaviour of Nitrided Layer of 42CrMo4 Steel. \\ International Journal of Materials Science and Applications. Vol. 6, No. 1, 2017, pp. 18-27. doi: 10.11648/j.ijmsa.20170601.13
}

Received: August 12, 2016; Accepted: August 25, 2016; Published: January 4, 2017

\begin{abstract}
Steel $42 \mathrm{CrMo} 4$, used in the manufacturing of transmission systems (gears), poses problems in service under specific cyclic stress conditions of the operating mode of its bodies. The treatment of ion nitriding during 20 hours with $520^{\circ} \mathrm{C}$ applied to $42 \mathrm{CrMo} 4$ steel in an untreated state (quenched and tempered) led to the formation of a compound layer (mixture of nitrides $\gamma^{\prime}$ and carbonitrides $\varepsilon$ with irregular thickness evaluated at $5 \mu \mathrm{m}$ and a diffusion layer of depth equal to $\left.295 \mu \mathrm{m}\right)$. In the diffusion layer, the presence of inserted nitrogen leads to the increase in hardness ( 3 times that of basic material) and to the creation of a compressive residual stress field (-400MPa). This superficial hardening does not modify the tensile mechanical characteristics of $42 \mathrm{CrMo} 4$ steel but renders it more sensitive to overload in fatigue. As a result, a $0.7 \%$ total deformation imposed corresponding to a loading level of $850 \mathrm{MPa}$, constitutes the limit of gain in fatigue obtained by the ion nitriding considered.
\end{abstract}

Keywords: 42CrMo4 Steel, Nitriding, Work-Hardening, Residual Stress, Low Cycle Fatigue

\section{Introduction}

The experiments show that fatigue cracks, generally starting on the surface, are at the origin of the damage and the rupture of the majority of the parts subjected to cyclic efforts quite lower than the material elastic limit. The nitriding occupies a good place in the thermochemical treatments of superficial hardening. Its relatively low temperature $\left(450-570^{\circ} \mathrm{C}\right)$ compared to a carburising treatment $\left(>900^{\circ} \mathrm{C}\right)$, limits considerably thermal distortions.

The interest of this treatment in the industrial applications justifies the number of studies which were devoted to this subject [1-9]. This reveals that the in-depth penetration crack resistance of hardening elements $\left(\mathrm{N}_{2}\right)$, of the hardness of these layers $[4,5,6,8]$ as well as the distribution of the residual stresses [7, 9, 10]. This beneficial effect of the treatment can be reduced or even reversed under the overload conditions, representative of the transient mode of transmission systems (gears, shafts, etc...) $[10,11,13,16,19]$. Thus the overload sensitivity of the nitrided parts became a significant parameter in the qualification in the treatment of superficial hardness. This sensitivity is closely related to the surface integrity of the nitrided parts. The aim of this study is to check the behaviour low cycle fatigue nitrided layers and to determine the fatigue gain limit of these layers.

\section{Material and Treatment}

The studied material is a low alloy of $42 \mathrm{CrMo} 4$ steel, used in the mechanical engineering industry for the manufacturing of transmission systems (gears) and of injection moulds (for plastics). Its chemical composition is defined in table 1. The untreated structure is of tempered martensite type. An ion nitriding was applied to a series of mechanical specimens, tension and lowcycle fatigue, under the conditions defined in table 2. 
Table 1. Chemical composition of studied steel.

\begin{tabular}{|c|c|c|c|c|c|c|c|c|c|c|c|c|}
\hline Element & C & Mn & $\mathbf{S i}$ & $S$ & $\mathbf{C r}$ & $\mathbf{P}$ & Mo & $\mathbf{N i}$ & Al & $\mathrm{Cu}$ & $\mathbf{T i}$ & $\mathrm{Fe}$ \\
\hline Teneur (\%) & 0.41 & 0.77 & 0.28 & 0.026 & 1.02 & 0.019 & 0.16 & 0.16 & 0.04 & 0.25 & 0.03 & bal. \\
\hline
\end{tabular}

Table 2. Ion nitriding conditions.

\begin{tabular}{|c|c|c|c|c|}
\hline \multirow{2}{*}{ Steel } & \multicolumn{4}{|c|}{ Parameters } \\
\hline & $\theta\left({ }^{\circ} \mathrm{C}\right)$ & $t(H)$ & Nitrogen (\%) & Hydrogen (\%) \\
\hline $42 \mathrm{CrMo} 4$ & 520 & 20 & 20 & 80 \\
\hline
\end{tabular}

\section{Experiments}

The identification of the nature of the layers was carried out by X-rays diffraction analyses and metallographic tests under the optic microscopes and Scanning Electronic Microscope (SEM). The control of hardness caused by nitriding was carried out by microhardness tests ( $\mathrm{HV}{ }_{0,0} 5 \mathrm{on}$ transverse sections). The state of residual stresses in the nitrided layer was determined at the ambient temperature by $\mathrm{X}$-rays diffraction on the surface, and by the incremental hole method in under layers. The modifications of the basic mechanical characteristics, consecutive to the nitriding treatment, were evaluated by conventional tensile tests on standardized specimens $(\phi 6)$ (fig. la). The damaging mode of the hardened layers under tension static loading was determined by micrographic examinations of the surfaces and microfractographic of the ruptured topographies under the Scanning Electronic Microscope (SEM).

Low cycle fatigue tests at rates of total imposed deformation $(0.5,0.6,0.7,0.8,0.9,1 \%)$ were carried out on steel $42 \mathrm{CrMo} 4$ specimens in a untreated and in a nitrided states (fig. 1b). These tests took place with a loading ratio $\mathrm{R}$ $=-1$ and under a frequency $v=1 \mathrm{~Hz}$. The upper and the surface fracture of the test-specimens broken in lowcycle fatigue were examined under the SEM.

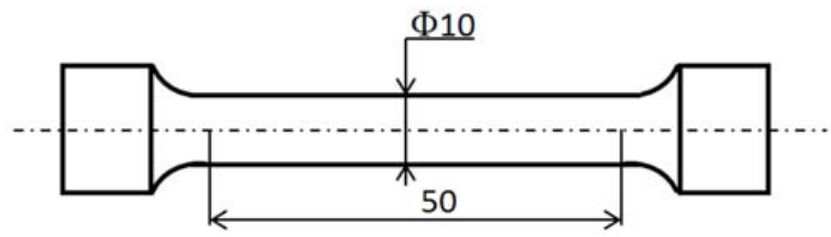

a) Tensile specimen

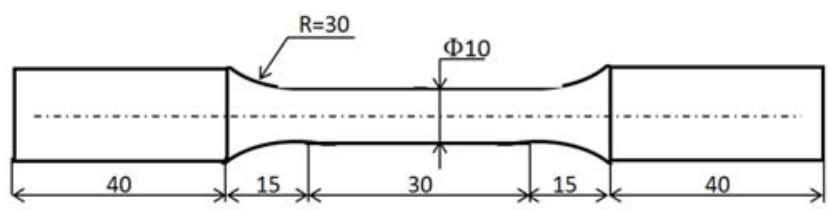

b) Low cycle fatigue test specimen

Fig. 1. Geometry of the used specimens.

\section{Results}

\subsection{Characterization of the Nitrided Layer}

\subsubsection{Structure and Hardening}

The ion nitriding treatment led to a hardened depth approximately equal to $350 \mu \mathrm{m}$ with a maximum hardness, slightly in under layer, almost equal to the double of that measured in core (fig. 2).

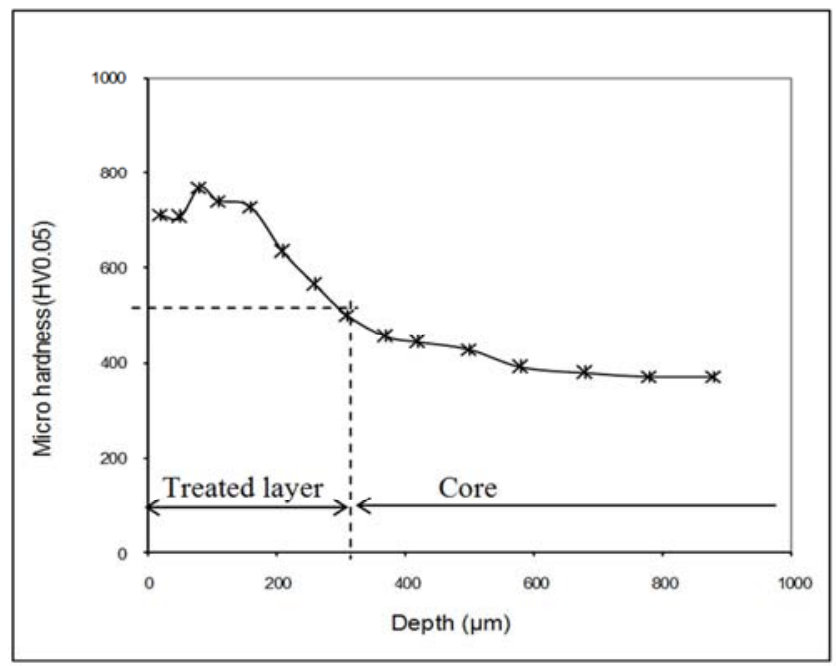

Fig. 2. Hardness profile by the ion nitriding.

The metallographic test of a transverse section, a structure with three layers (fig. 3):

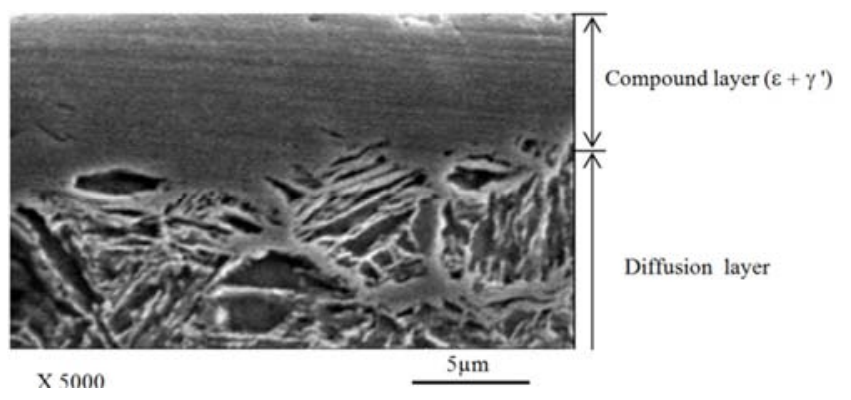

Fig. 3. Layer structure of the nitrided steels on a transverse section.

* a compound layer with an irregular thickness going from $3 \mu \mathrm{m}$ to $5 \mu \mathrm{m}$. On the surface, this layer presents at the SEM a granulous aspect and appears to be made up of spherical particles of sizes varying from $2 \mu \mathrm{m}$ to $7 \mu \mathrm{m}$ (fig. 4). The Xrays diffraction analysis shows that it is a layer made up of a mixture of the phases $\varepsilon\left(\mathrm{Fe}_{2-3} \mathrm{CN}\right)$ and $\gamma^{\prime}\left(\mathrm{Fe}_{4} \mathrm{~N}\right)$ (fig. 5);

* a diffusion layer made up of nitrogen solid solution in insertion with a thickness close to $340 \mu \mathrm{m}$; it is marked by the carbide precipitation probably related to the carbon gradient diffusion in the opposite direction of nitrogen (fig. 6);

$*$ in core, a structure of tempered martensite resulting from the preliminary heat treatment. 


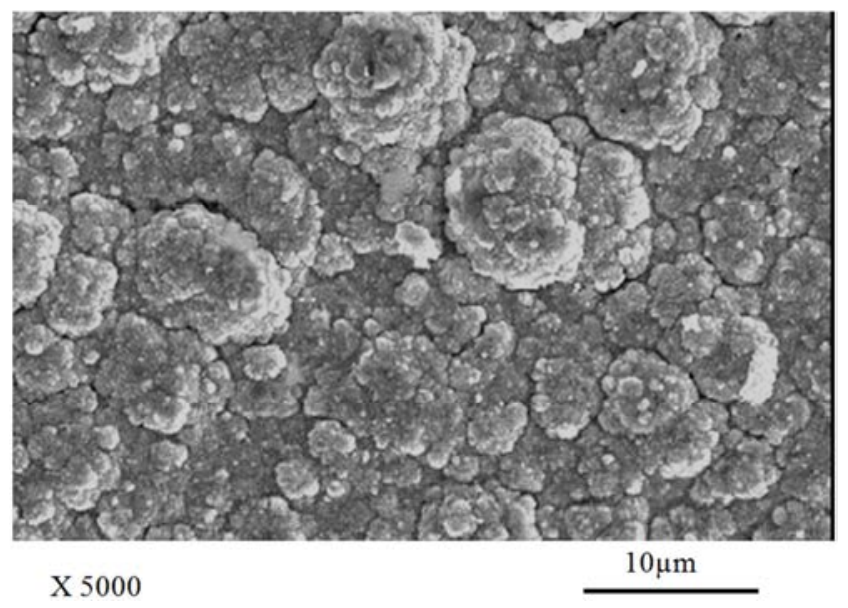

Fig. 4. Morphology of the compound layer - surface Examination.

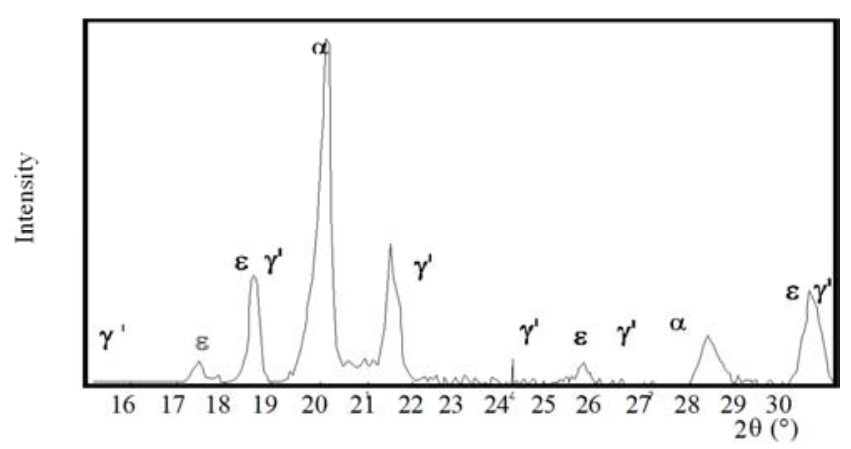

Fig. 5. X-rays diffraction Identification of the compound layer components $(\varepsilon+\gamma)$.

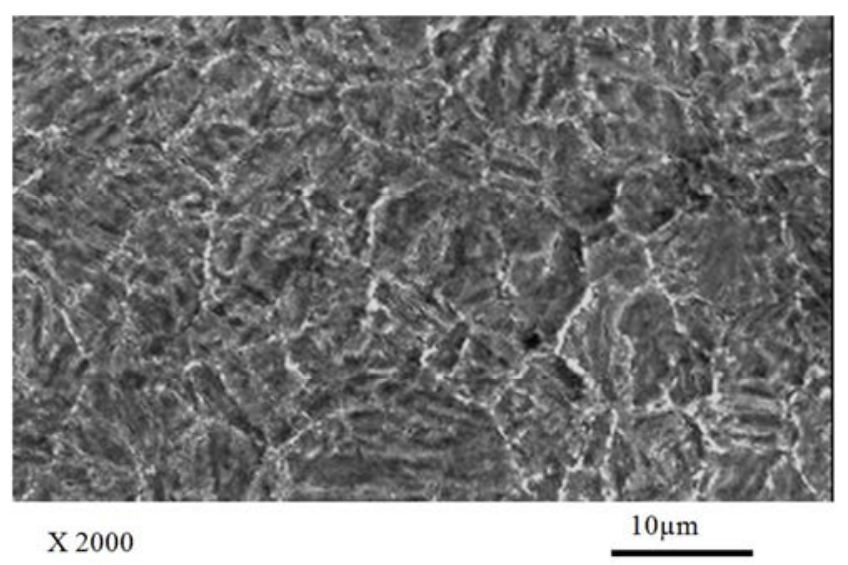

Fig. 6. Structure gradient in the nitrided layer.

\subsubsection{Residual Stresses Distribution.}

The compressive residual stresses with profile width comparable to those of microhardness is induced by the structural transformations characterized by the formation of nitrides and carbonitrides in the compound layer and the micro distortions related to the nitrogen insertion in the diffusion layer in the two principal directions of the specimen (longitudinal and circumferential). The level of these compressive stresses decreases from the surface towards the core to reach in under layer, at approximately $0,5 \mathrm{~mm}$ of the surface, very low values or slightly tension (fig. 7).

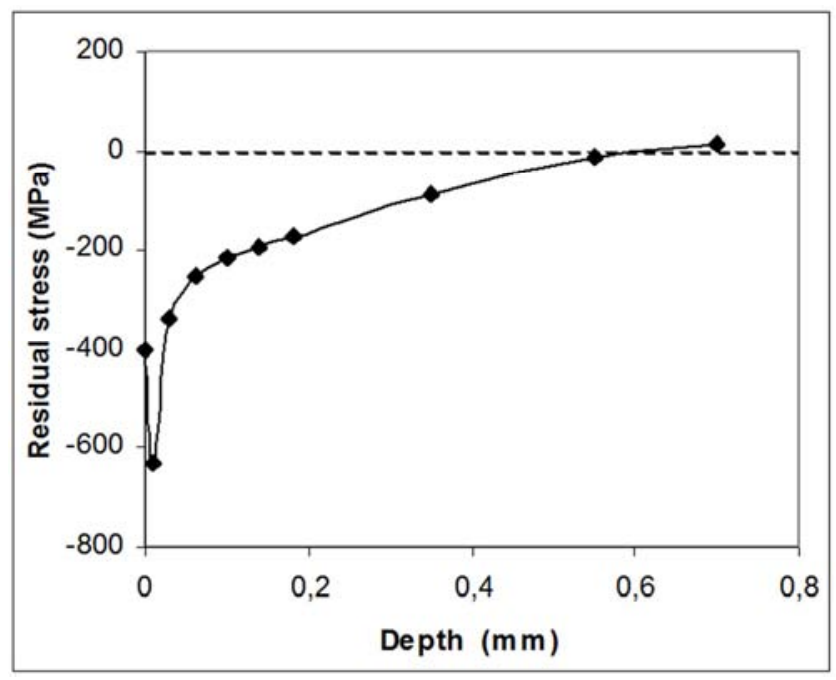

Fig. 7. Residual stress distribution in the nitrided layers.

\subsection{Influence of the Nitriding on the Tensile Mechanical Characteristics}

\subsubsection{Mechanical Characteristics}

The tensile mechanical characteristics and hardness in the two studied states (untreated and nitrided) as well as the laws of monotonous consolidation are defined in table 3. It results a significant lowering from ductility (A(\%): 16.5 to 6$)$ associated to a light hardening of the material (increase in $\mathrm{Rp}_{0.2}$ ). The tension consolidation of the two states of the $42 \mathrm{CrMo} 4$ steel obeys a law of Hollomon type $\left(\sigma=\mathrm{K}\left(\varepsilon_{\mathrm{p}}\right)^{\mathrm{n}}\right)$ with the characteristics $\mathrm{K}$ and $\mathrm{n}$ presented in table 3 . It results a considerable consolidation of the nitrided layer marked a rate hardening value (n) almost equal to twice of the untreated state.

Table 3. Mechanical characteristics of tensile and hardness.

\begin{tabular}{|c|c|c|c|c|c|c|c|}
\hline \multirow{2}{*}{ State } & \multicolumn{2}{|c|}{ Mechanical characteristics } & \multicolumn{3}{|c|}{ Hardness } & \multicolumn{2}{|c|}{ Monoton consolidation $\left(\sigma=K\left(\varepsilon_{p}\right)^{n}\right)$} \\
\hline & $\mathbf{R}_{\mathrm{p} 0,2}$ (MPa) & $\mathbf{R}_{\mathrm{m}}(\mathrm{MPa})$ & $A_{t}(\%)$ & E (GPa) & $H_{V_{0,1}}$ & K(MPa) & $\mathbf{n}$ \\
\hline Untreated & 978 & 1050 & 16.5 & 201 & 356 & 1026 & 0.024 \\
\hline Nitrided & 1030 & 1070 & 6 & 204 & 1090 & 1062 & 0.049 \\
\hline
\end{tabular}

The layouts of the tensile conventional curves, starting from ambient tests on smooth cylindrical specimens, highlight in the case of the nitrided state deflections starting from the elastic limit associated most probably to the brutal rupture of the compound layer of $\left(\gamma^{\prime}+\varepsilon\right)$ hard and brittle (fig. 8). 


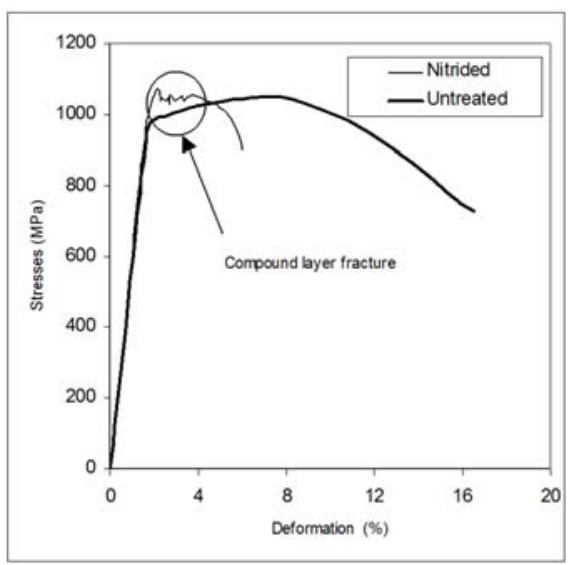

Fig. 8. Tensile Conventional curves.

\subsubsection{Rupture Mode}

The microfractographic study makes it possible to elucidate the influence of the conditions of nitriding on the resistance to cracking under tensile load of the nitrided layers

* The SEM examination, of the upper of tensile specimens, highlights several helicoidally ruptures parallel to each other, appearing under tensile load corresponding to the deflections observed on the curve i.e. when the allowable deformation of these layers is reached (fig. 9).

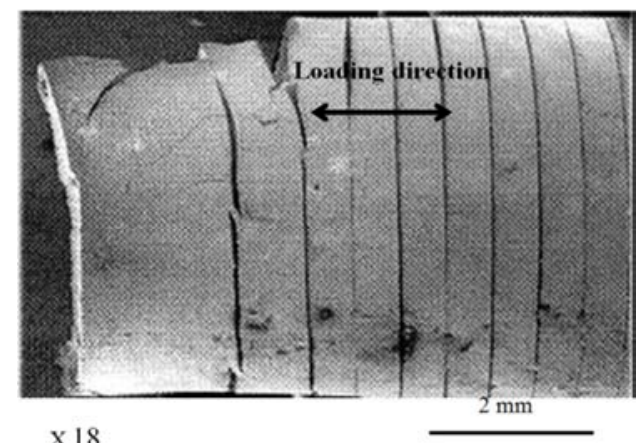

Fig. 9. Great sensitivity to cracking and brittle fracture by tension of the nitrided layer.

* High magnification examination, reveals that these cracks are born starting from the porosities generated by nitriding treatment (fig. 10a), then grow under the effect of the loading (fig. 10b)and coalescent to lead to the final rupture (fig. 10c).

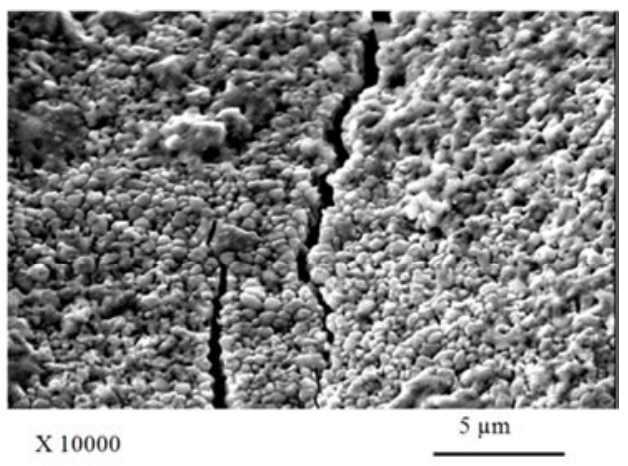

a) Crack initiation

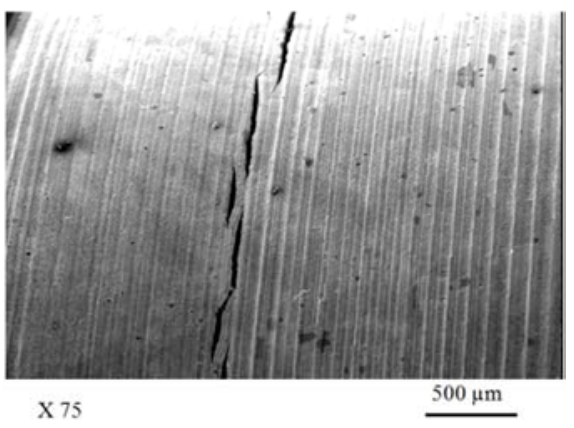

b) Growth of the fissures

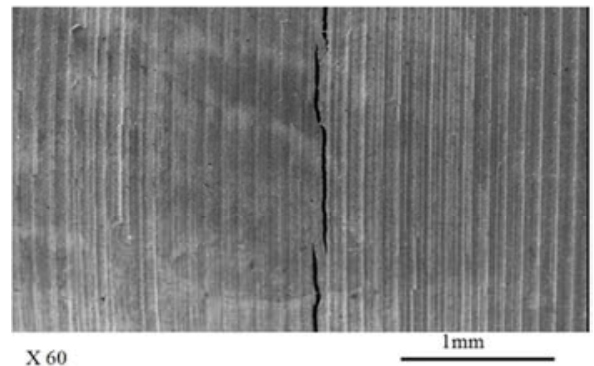

c) Coalescence of the fissures

Fig. 10. Mechanism of cracking of the parts nitrided under tensile loading.

* The microfractographic analysis of the ruptured topography confirms the observations on the surface and reveals typical faces of a brittle fracture of all the treated layer (fig. 11). This lightly brittle behaviour of the hardened layer is at the origin of the premature tensile rupture of the nitrided state and makes it possible to explain the significant fall of ductility $(6 \%)$ compared to the untreated state $(16.5 \%)$.

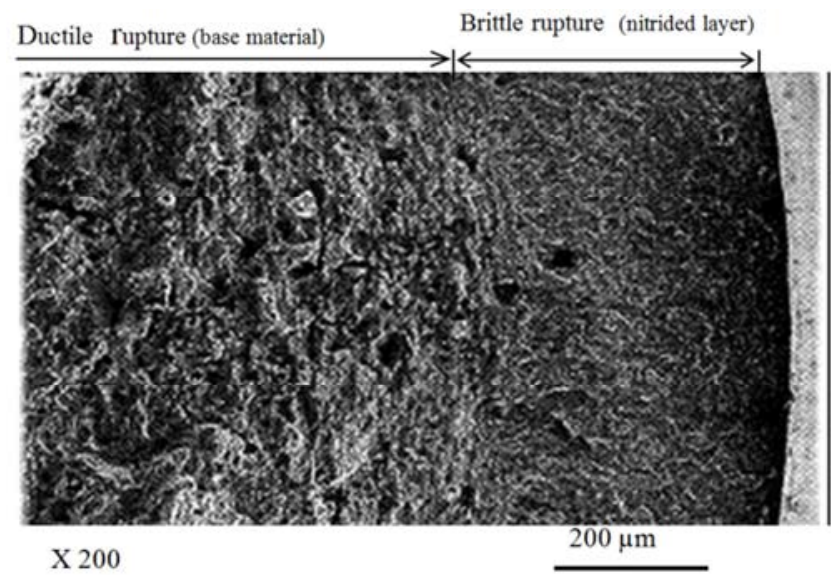

Fig. 11. Surface fractures associated with tension rupture.

* the examination with strong enlargements of the fracture topography highlights three different zones (fig. 12):

- brittle zone of fracture near the surface thickness, comparable with that of the nitrided layer, where one finds fine precipitates, generated by the nitrogen diffusion in the matter;

- transition zone of brittle / ductile fracture at approximately $500 \mu \mathrm{m}$ from the surface;

- ductile zone of rupture with cups in basic material. 


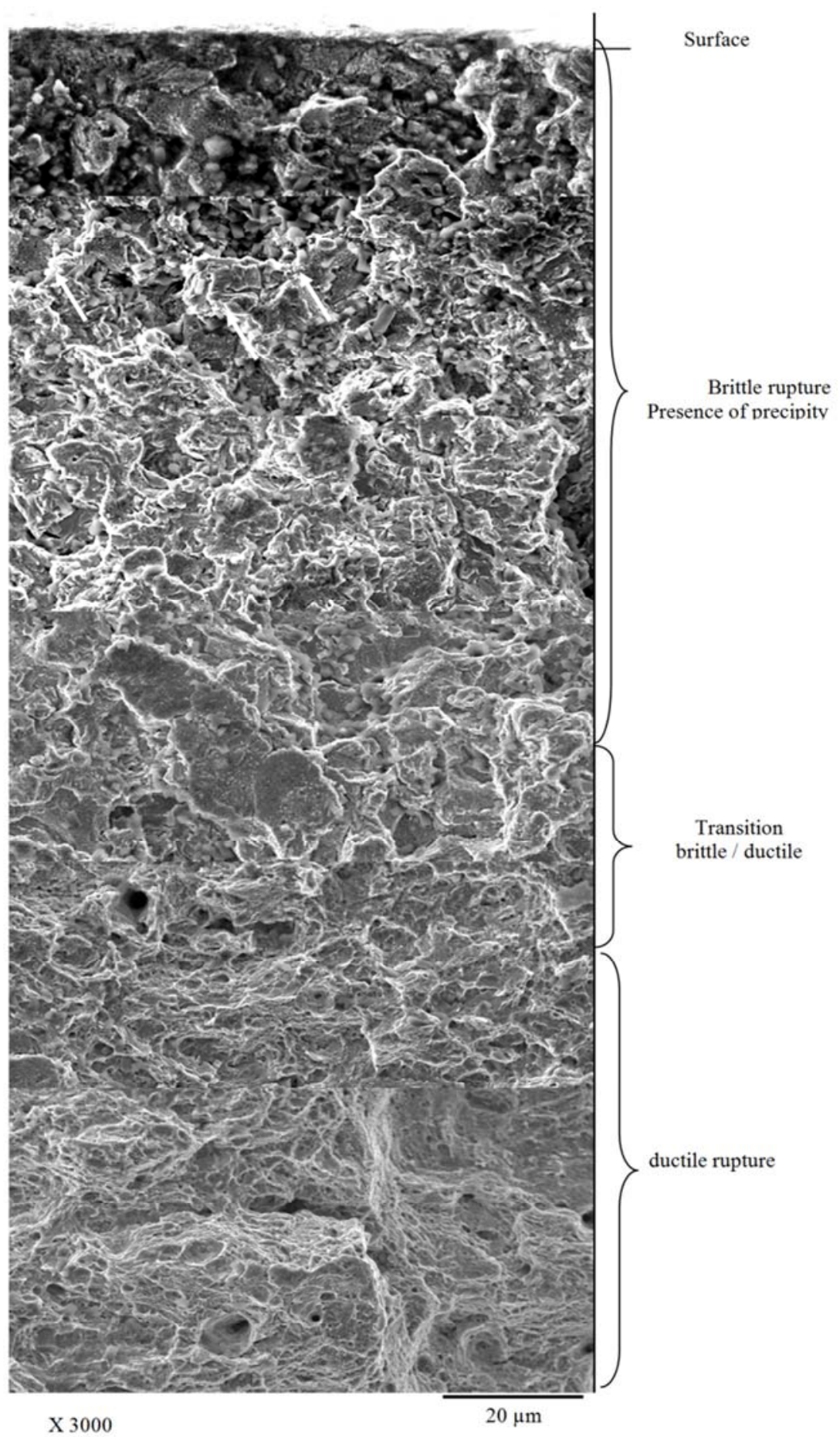

Fig. 12. Tensile fracture topography of nitrided $42 \mathrm{CrMo} 4$ steel.

\subsection{Overload Fatigue Sensitivity}

The lowcycle fatigue tests highlight an accommodation of material in these two states subjected to a total imposed deformations going from 0.55 to $1.6 \%$. One observes a phenomenon of softening which results in a progressive fall of the amplitude of the stress for a imposed deformation as a function of the number of cycles (fig. 13). This progressive fall, much more marked for the first 30 cycles, continues until the rupture. No phenomenon of saturation was highlighted for the two studied states (fig. 14). In the absence of the saturation phenomenon for all rates of total imposed deformations during low cycle fatigue tests, one refers to the parameters of the most stable cycle to establish the cyclic law of consolidation which takes the form $\Delta \sigma / 2=\mathrm{K}^{\prime}\left(\Delta \varepsilon_{\mathrm{p}} / 2\right)^{\mathrm{n}}$ where $\Delta \sigma / 2$ represent the maximum stress amplitude reached during the reference cycle and $\Delta \varepsilon_{\mathrm{t}} / 2$ the amplitude of imposed deformation (fig. 15). 


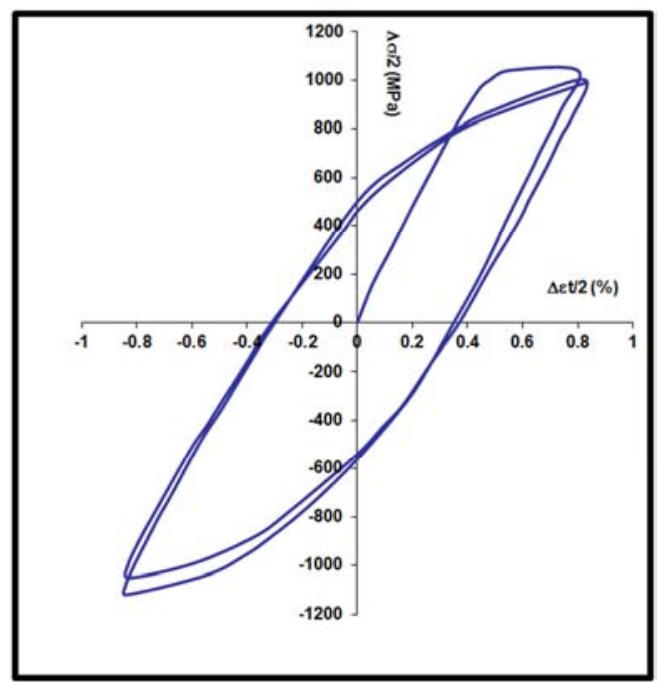

a) Untreated

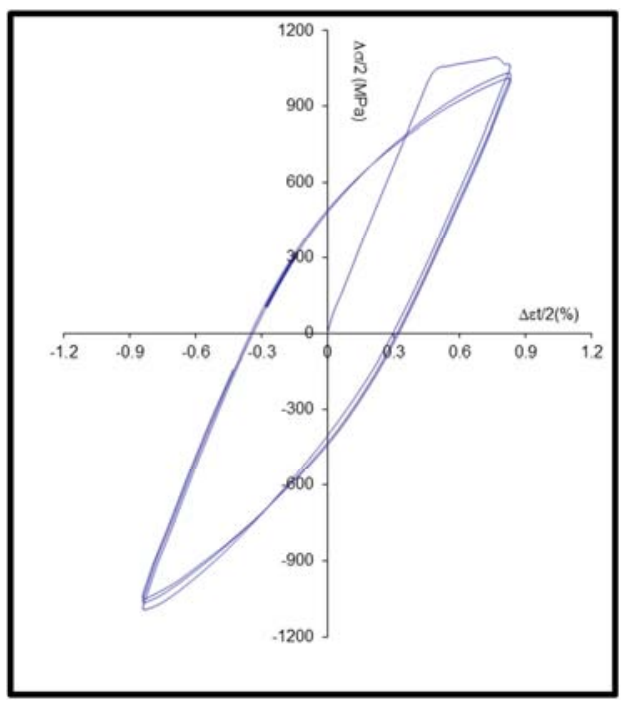

b) Nitrided

Fig. 13. Hysteresis loops of the two studied states $\left(\Delta \mathcal{E}_{t} / 2= \pm 0.85 \%\right)$.

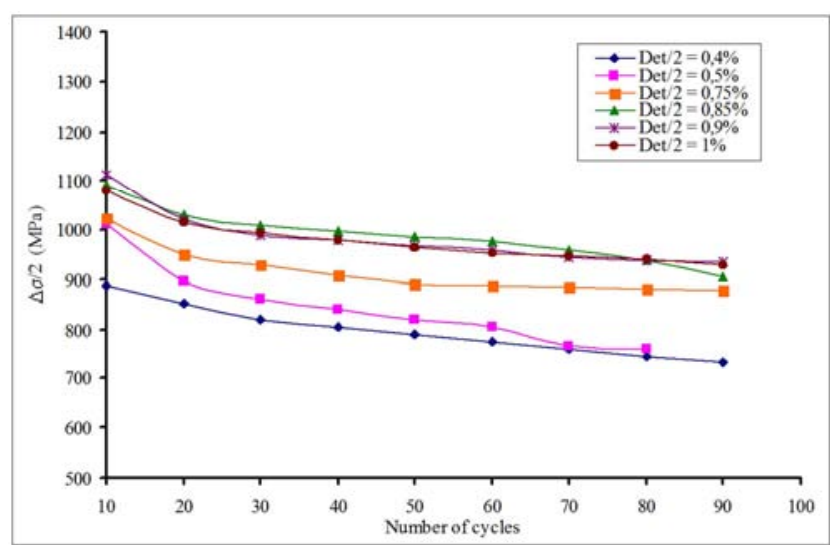

Fig. 14. Evolution of the applied stresses according to the cycle number. Nitrided state.

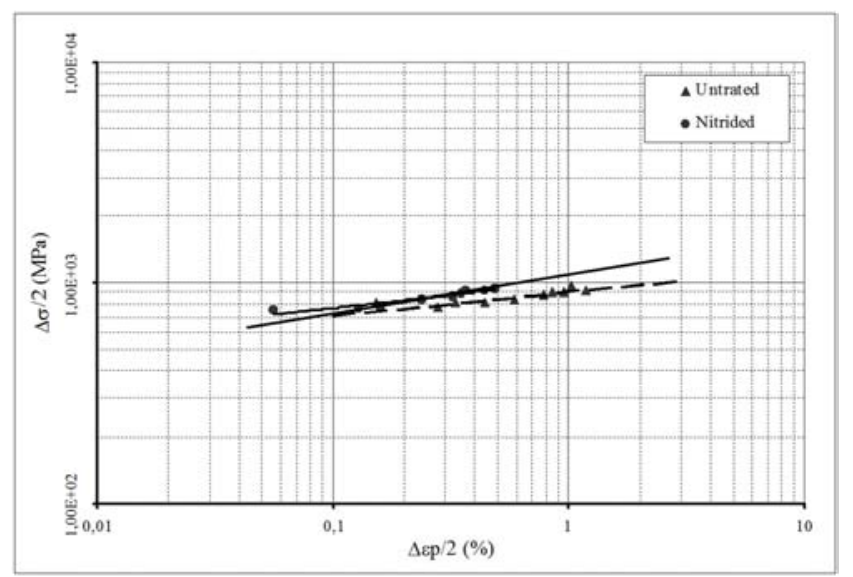

Fig. 15. Logarithmic representation of the cyclic consolidation curves.

The laws of cyclic consolidation of the two studied states are gathered in table 4. This reveals that the cyclic coefficient of consolidation ( $\mathrm{n}$ ') of the nitrided state is smaller than monotonous coefficient, this results in a faster softening phenomenon as in an untreated state.

Table 4. Laws of cyclic consolidation, Basquin and Manson-Coffin for the two studied states.

\begin{tabular}{llll}
\hline State & Cyclic consolidation law & Basquin law & Manson-coffin law \\
\hline Untreated & $\Delta \sigma / 2=907\left(\Delta \varepsilon_{\mathrm{p}} / 2\right)^{0.089}$ & $\Delta \varepsilon_{\mathrm{e}} / 2=0.587\left(2 \mathrm{~N}_{\mathrm{f}}\right)^{-0.05}$ & $\Delta \varepsilon_{\mathrm{p}} / 2=4.72\left(2 \mathrm{~N}_{\mathrm{f}}\right)^{-0.67}$ \\
Nitrided & $\Delta \sigma / 2=999\left(\Delta \varepsilon_{\mathrm{p}} / 2\right)^{0.114}$ & $\Delta \varepsilon_{\mathrm{e}} / 2=0.59\left(2 \mathrm{~N}_{\mathrm{f}}\right)^{-0.045}$ & $\Delta \varepsilon_{\mathrm{p}} / 2=1.25\left(2 \mathrm{~N}_{\mathrm{f}}\right)^{-0.2}$ \\
\hline
\end{tabular}

The superposition of the Morrow curves $\left(\Delta \varepsilon_{\mathrm{t}} / 2\right.$ as a function of $2 \mathrm{~N}_{\mathrm{F}}$ ) related to the two studied states highlights the limit of gain in low cycle fatigue brought by the ion nitriding (fig. 16). It results from this that a rate of critical imposed total deformation $\left(\Delta \varepsilon_{\mathrm{t}} / 2=0.7 \%\right)$ corresponding toa loading amplitude $(\Delta \sigma / 2=850 \mathrm{MPa})$ beyond which, the nitriding will have no interest in term of fatigue strength, expressed in fatigue life (number of cycle at rupture $\mathrm{N}_{\mathrm{F}}$ ). On the other hand for smaller rates of deformation corresponding to lower stress level, the improvement of the fatigue behaviour with the nitriding is significant in term of fatigue life. The number of cycles at the rupture is approximately 4 to 10 times higher than that of the untreated state.

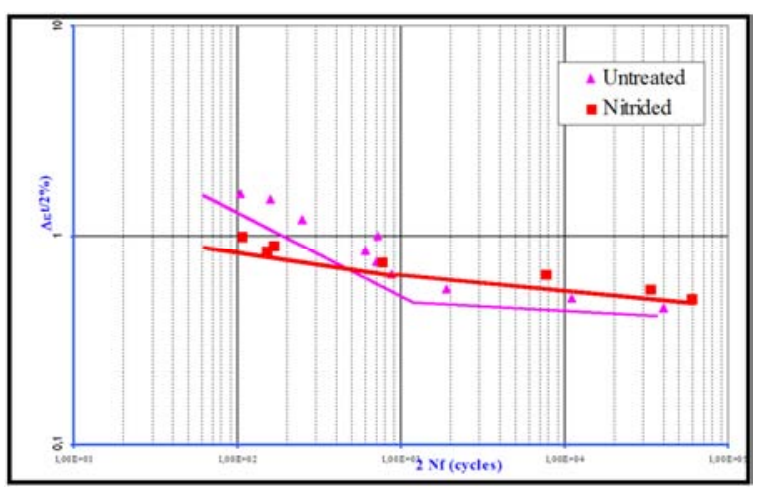

Fig. 16. Low cycle fatigue strength of the nitrided layer. 


\subsection{Microfractographic Analysis}

The SEM examination of the upper specimens broken by lowcycle fatigue, illustrates a distribution of cracks near the rupture (fig. 17) Some of them seem to have originated from the growth and the coalescence of micro porosities in the compound layer (fig. 18)

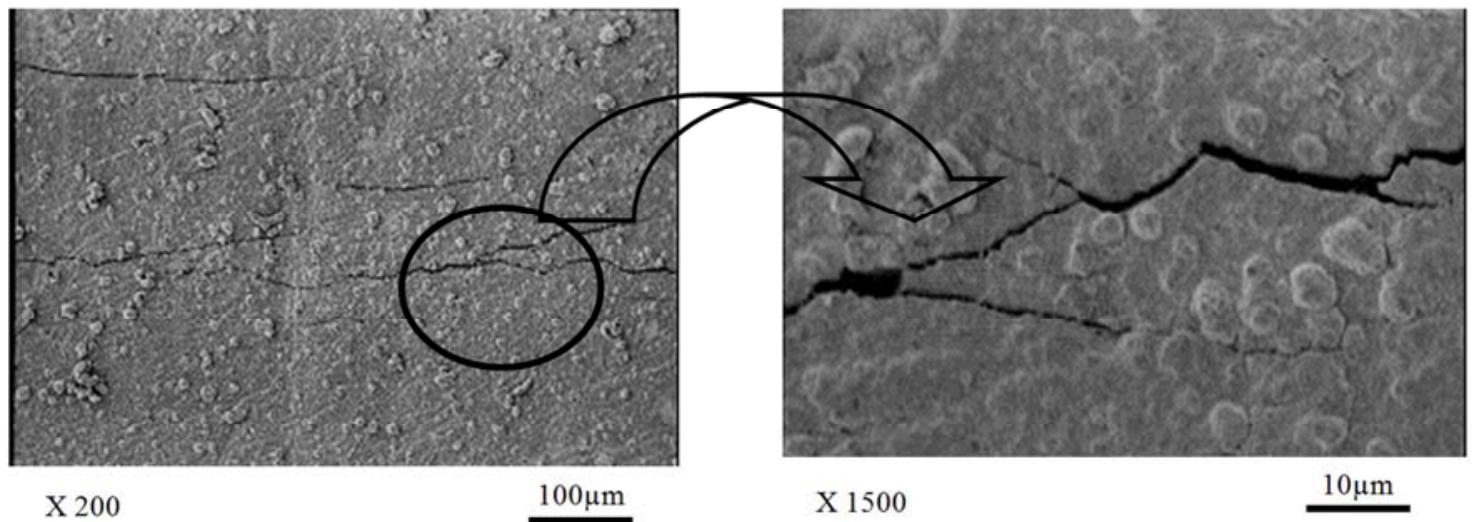

Fig. 17. Fractures ramification Nitrided state $\left(\Delta \varepsilon_{t} / 2= \pm 1 \% ; N_{F}=54\right.$ cycles $)$.

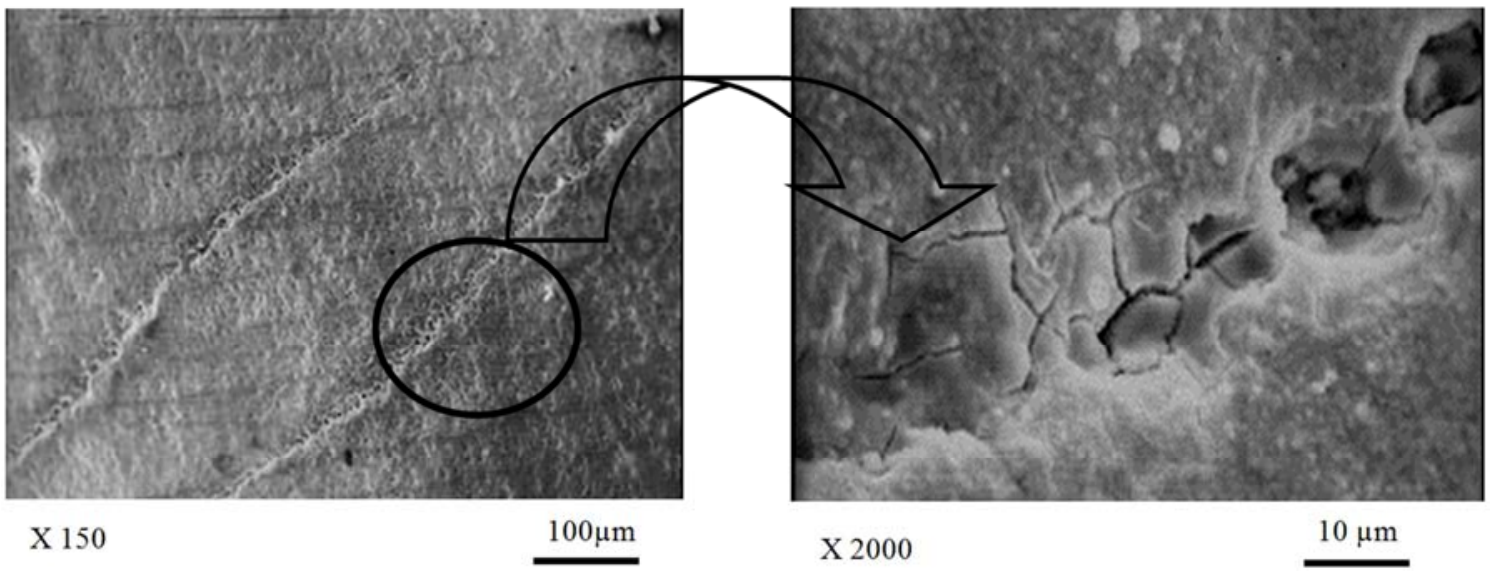

Fig. 18. Micro porosities coalescences in the white layer of a radial fissure. Nitrided state $\left(\Delta \mathcal{E}_{t} / 2= \pm 0,85 \% ; N_{F}=67 \mathrm{cycles}\right)$.

The microfractographic analysis of fracture topography shows the presence oftypical surface fracture of fatigue characterized by a crack nucleation followed by a propagation and brutal rupture zones (fig. 19). The surface fracture corresponding to the nitrided state is marked by a smooth rupture zone corresponding to the treated thickness, including several radial cracks (fig. 20a). On the other hand, the surface fracture of the untreated state appear brittle and relatively homogeneous aspect characterized by fatigue scratches (fig. 20b).

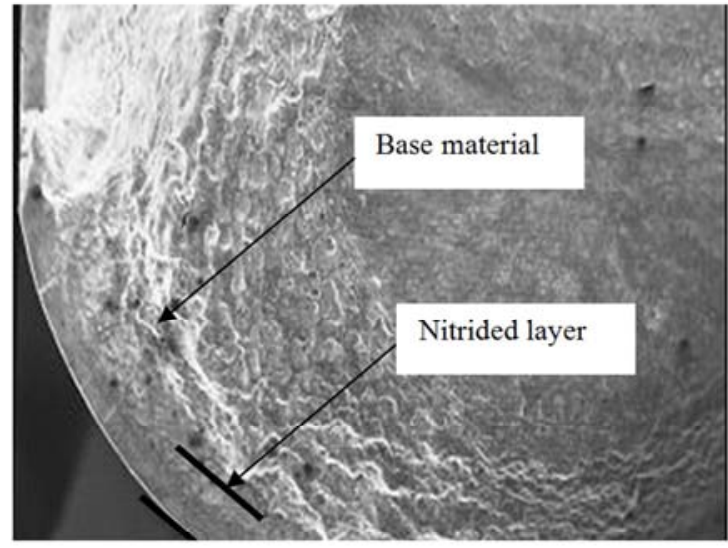

X 15

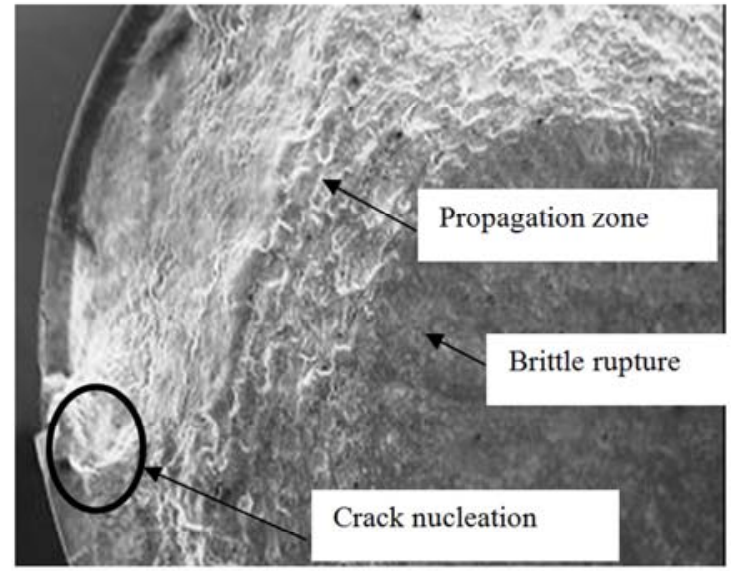

$\mathrm{X} 15$

$1 \mathrm{~mm}$

Fig. 19. Low cycle fatigue fracture topography aspect of the nitrided layer. Nitrided state $\left(\Delta \mathcal{E}_{t} / 2= \pm 0,5 \% ; N_{F}=41150\right.$ cycles $)$. 


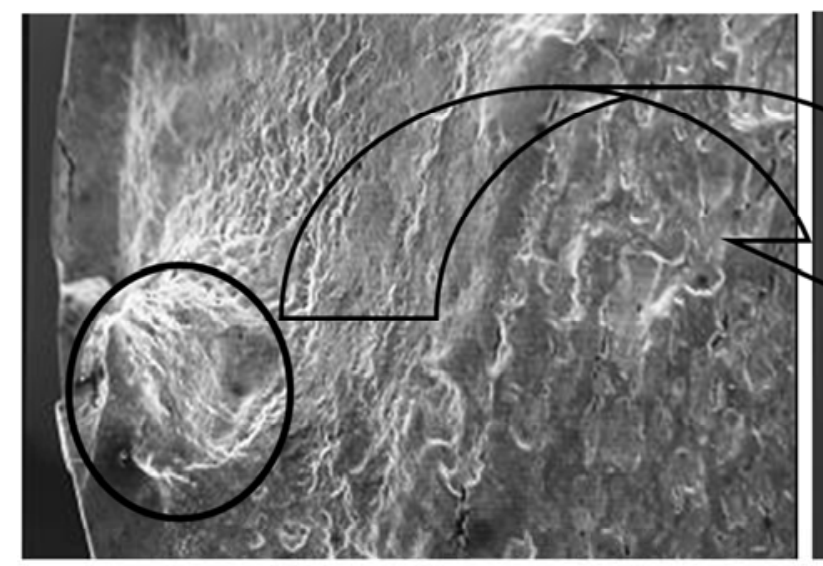

X 35

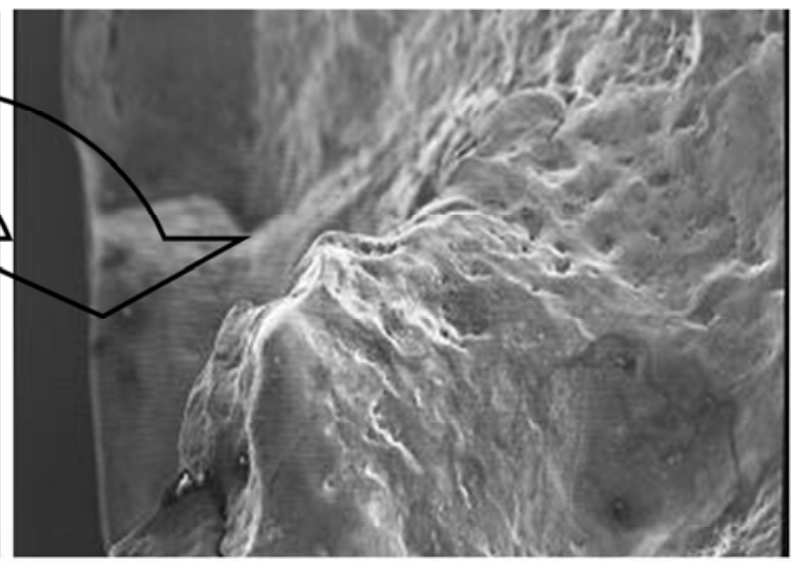

$\mathrm{X} 100$

$100 \mu \mathrm{m}$

a) Nitrided state: $\Delta \varepsilon_{\mathrm{t}} / 2= \pm 0,65 \% ; \Delta \sigma / 2=865 \mathrm{MPa} ; \mathrm{N}_{\mathrm{F}}=858$ cycles

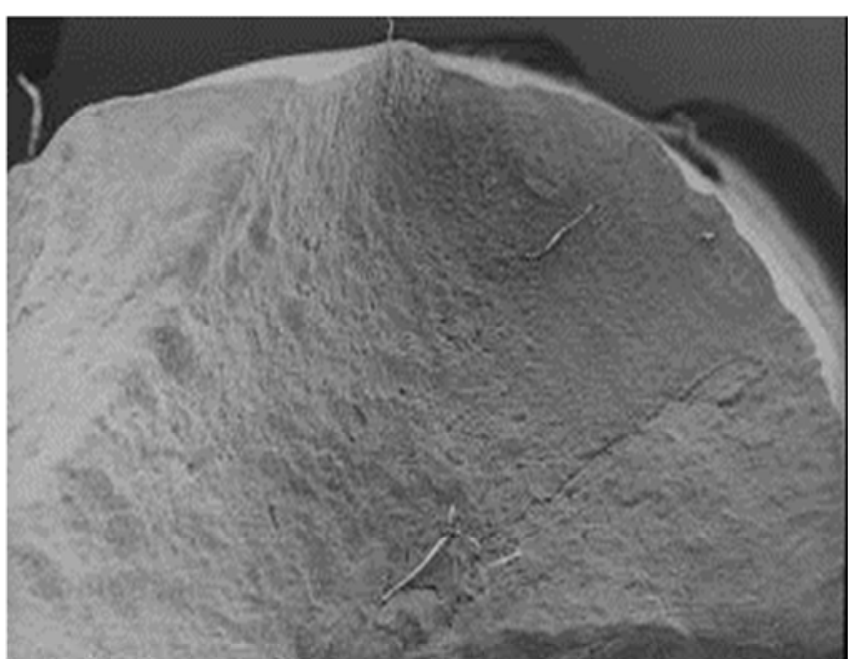

X 15

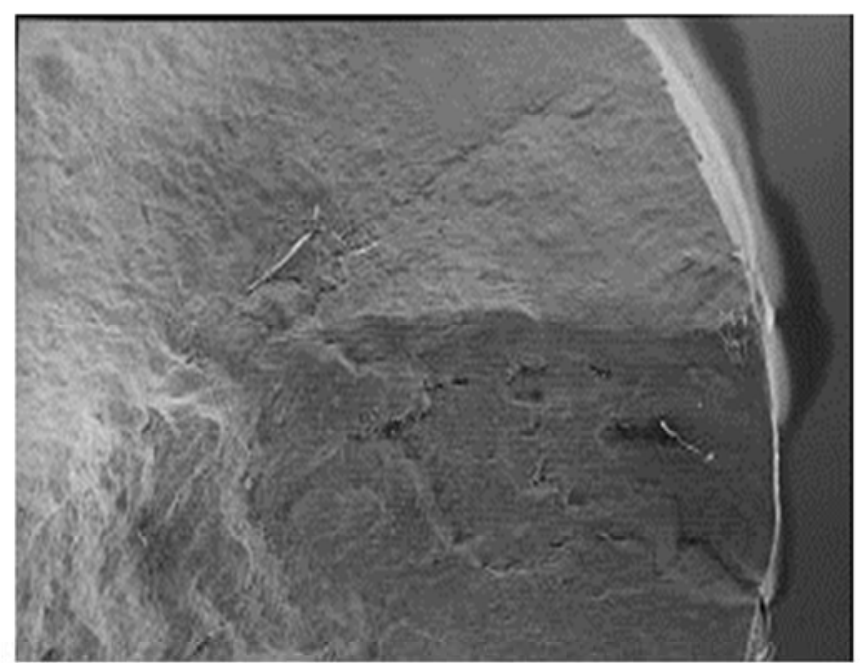

X 15

$1 \mathrm{~mm}$

b) Untreated state: $\Delta \varepsilon_{\mathrm{t}} / 2= \pm 0,65 \% ; \Delta \sigma / 2=776 \mathrm{MPa} ; \mathrm{NR}_{\mathrm{F}}=872$ cycles

Fig. 20. Low cycle fatigue fracture topography aspect.

Table 5. Comparative State of the layers properties.

\begin{tabular}{llll}
\hline & $\begin{array}{l}\text { untreated } \\
\text { (base material) }\end{array}$ & Nitrided & \\
\cline { 3 - 4 } & 201000 & 204000 & Moyen properties of the treated layer \\
\hline Young modolus: $\mathrm{E}(\mathrm{MPa})$ & 16.5 & 6.5 & $218000^{*}$ \\
$\mathrm{~A}(\%)$ & 1050 & 1070 & 1.9 \\
Ultimate tensile $(\mathrm{MPa})$ & 978 & 1030 & $>1200$ \\
Yield stress: $\mathrm{R}_{\mathrm{p}(0.2)}(\mathrm{MPa})$ & & - \\
\hline
\end{tabular}

\section{Discussion}

\subsection{Tensile Behaviour}

The small increase in the elastic limit and the tensile strength ( 2 to $5 \%$ ) of the nitrided state, compared to the untreated state, is the direct consequence of a superficial surface which modifies only the properties of a thin layer $[10,20,21]$. Thus, the resistance of the nitrided specimen remains controlled by the volume of basic material, whereas its ductility, slightly reduced, depends on the behaviour of the compound layer and the rate of superficial hardening. This ductility reduction is attributed to the nitrided heterogeneity and the introduction of a multi axial stresses state which rises from the difference of the Poisson's ratios when the basic material is plasticised, whereas the surface layers continue to have an elastic behaviour $[11,13,16]$. The helicoidally ruptures observed on the surface of the nitrided tensile specimens could justify the multi axial stresses state due to the difference in behaviour between core and layer of different elastic modulus. These modulus were determined from a simple model with two springs of different stiffness's assembled in parallel (fig. 21). 


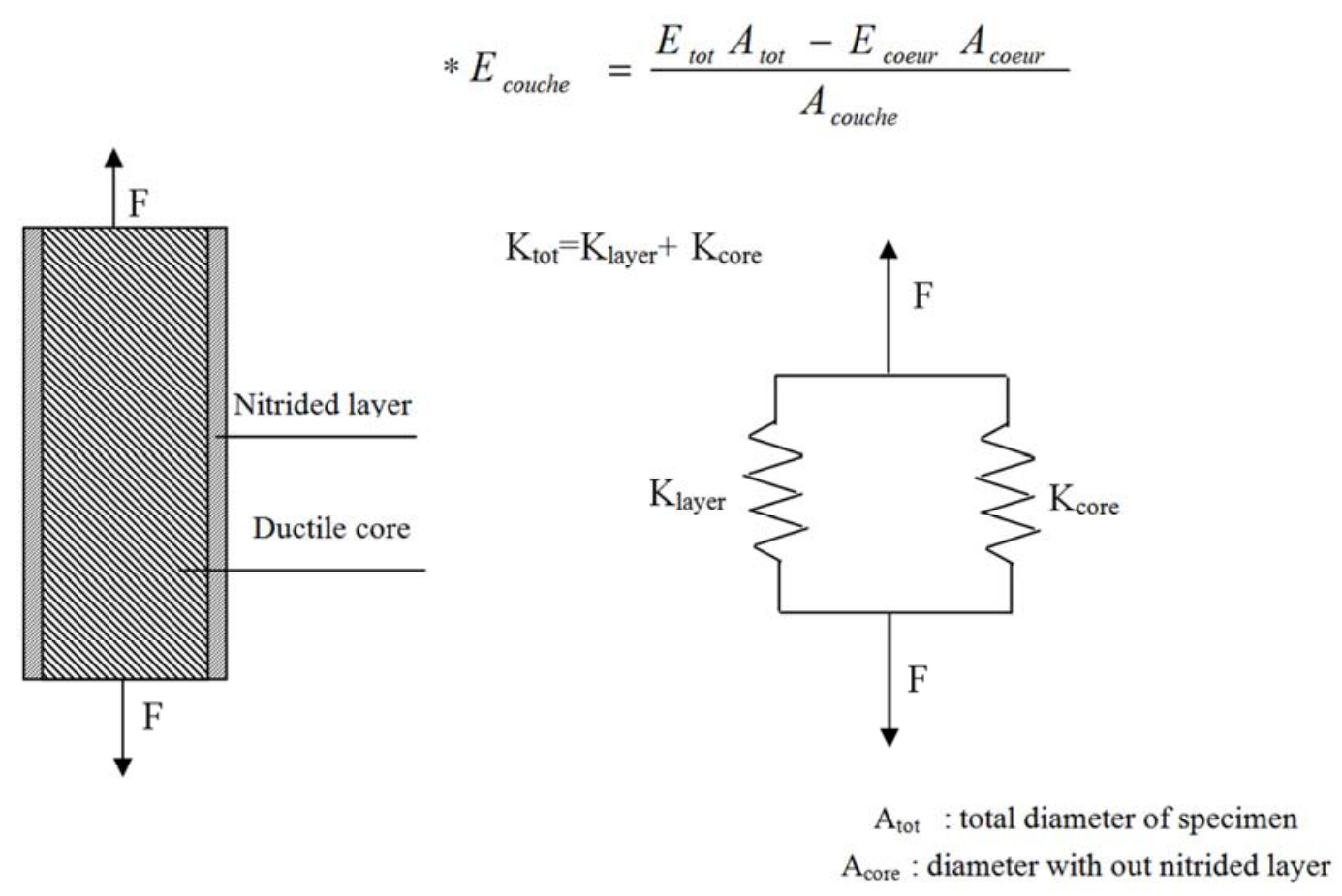

Fig. 21. Rigidities of the hardened layers [11].

The results, presented in table $\mathrm{V}$ show that even for a small deformation, the stress concentration induced by the ratio of the average Young module $\left(\mathrm{E}_{2} / \mathrm{E}_{1}=1.07\right)$, which is supported by the hardened layer is important in the compound layer where micro fissures are created and are the cause of rupture phenomenon. The ductility reduction evaluated with $62 \%$, after nitriding is caused by micro fractures without large deformation. The results of tensile test coupled with the micrographic examinations, confirm the significant brittleness of the compound layer $\left(\gamma^{\prime}+\varepsilon\right)$ which cracks after an acceptable total deformation slightly lower than $2 \%$ on a level of nominal stress about $1070 \mathrm{MPa}$ and a average stresses supported by the hardened layer well with the top of $1200 \mathrm{MPa}$.

\subsection{Overload Resistance}

In term of the number of cycles at rupture, a nitrided layer of $42 \mathrm{CrMo} 4\left(\mathrm{E}_{\mathrm{NR}}=300 \mu \mathrm{m}, \mathrm{HV} \max =1090\right)$ loses all its performances in fatigue when the rates of total deformation are equal to or higher than $0.7 \%$. Thus, a loading amplitude estimated at $850 \mathrm{MPa}$, can be regarded as the fatigue gain limits induced by the ion nitriding with respect to conditions described in table 2. Consequently, any overload creating a total deformation higher than $0.7 \%$ exposes the nitrided state to the brutal rupture in fatigue after a very reduced number of cycles (1000 cycles).

The numbers of cycles at rupture for nitrided states are smaller than those obtained on the untreated specimens. This difference in fatigue life behaviour can be explained by the effect of tensile and compressive cyclic stresses. At higher loading level, the damage of the nitrided layer is much higher than the surface basic material. An imposed total deformation of $0.7 \%$, corresponding to a loading level equal to $850 \mathrm{MPa}$ for the nitrided state and $775 \mathrm{MPa}$ for the untreated state, constitutes the fatigue gain limit of the ion nitriding.

\subsection{Residual Stresses Effect}

All the studies agree on the beneficial role of the compressive residual stresses induced by mechanical treatments $[9,13$,$] or thermo chemical [10,11,12,16,19]$ on fatigue crack resistance. These results obtained in the present study show a partial relaxation of these residual stresses on the surface of a specimen, broken under a cyclic loading and for an amplitude rather close to the ultimate stress fatigue gain caused by ion nitriding, $(\Delta \sigma / 2=$ $850 \mathrm{MPa})$. This relaxation under the effect of the cyclic loading (from - 400MPato -300MPa), could increase as fast as the loading amplitude is raised, which consequently involves a fall of fatigue crack resistance of the nitrided layer $[12,13,14,17,19,21]$.

\subsection{Surface Quality Effect on the Fatigue Rupture Mechanisms}

The microfractographic examinations of the broken specimens show an important effect of the surface quality on the fatigue resistance. Indeed the crack initiation always takes place at the surface of the nitrided or untreated states. The structural hardening of the surface layers consecutive to the precipitation of the phases $\varepsilon$ and $\gamma^{\prime}$ and the creation of a compressive residual stress field, proved to be effective for resistance to the fatigue crack initiation on the surface of specimen subjected to loading amplitudes that generate relatively smaller total deformations $\left(\Delta \varepsilon_{t} / 2 \leq 0.7 \%\right)$.

At higher deformation rates, the low ductility of the 
nitrided layers and the morphology of the compound layerare favourable to faster propagation of the cracks that generate premature fatigue ruptures.

Consecutive softening with the tensile and compressive cyclic stresses of the nitrided state is faster than that of untreated material especially for relatively high stress levels. This shows a less significant cyclic consolidation of the nitrided layer.

\section{Conclusion}

The ion nitriding during 20 hours at $520^{\circ} \mathrm{C}$, applied to the $42 \mathrm{CrMo} 4$ steel at the initial state, led to a superficial hardening characterized by the formation of compound and diffusion layers with a thickness close to $350 \mu \mathrm{m}$. The microstructural transformations on the level of these layers are at the origin of a hardening evaluated at $1090 \mathrm{HV}$ and a creation of a compressive residual stress field havinga maximum equal to $-500 \mathrm{MPa}$ and whose profile is comparable with that of the micro hardness.

The fatigue gain, expressed in number of cycles at rupture, brought by the ion nitriding is limited to the rates of imposed total deformations lower or equal to $0.7 \%$, corresponding to loading amplitudes $\Delta \sigma / 2 \leq 850 \mathrm{MPa}$.

The nitrided layers are relatively sensitive to the overloads $(\Delta \sigma / 2=850 \mathrm{MPa})$; they become subject to brittle fracture in fatigue by the appearance of several cracks in the white layer supported by the compressive residual stress relaxation.

\section{References}

[1] D. Ghigilione, H. P. Lieurade: Le rôle des traitements thermochimiques sur la tenue à la fatigue des composants mécaniques, (In French). Recueil de conférences du colloque national organisé par le CETIM etl'IUT de Troyes 4 et 5 décembre 1991.

[2] N. Limodin and Y. Verreman: Fatigue Strength Improvement of a 4140 Steel by Gas Nitriding: Influence of Notch Severity. Materials Science and Engineering A, (2006), p.435-436: 460-467.

[3] M. A. Terres, S. Ben Mohamed, H. Sidhom: Influence of ion nitriding on fatigue strength of low-alloy (42CrMo4) steel: Experimental characterization and predictive approach. International Journal of Fatigue, V.9 (2010) p.42-56

[4] K. Genel, M. Demirkol, M. Capa: Effect of ion nitriding on fatigue behaviour of AISI 4140 steel. Materials Science and Engineering A279 (2000) p.207-216.

[5] A. Celik, I. EfeogÆlu, G. Sakar: Microstructure and structural behavior of ion-nitrided AISI 8620 steel. Materials Characterization V.46 (2001) p.39-44.

[6] S. Ganesh, S. Raman, M. Jayaprakash: Influence of plasma nitriding on plain fatigue and fretting fatigue behaviour of
AISI 304 austenitic stainless steel. Surface and Coatings Technology V.201 (2007) p.5906-5911.

[7] P. Dela Cruz, M. Odén,T. Ericsson: Influence of plasma nitriding on fatigue strength and fracture of a B-Mn steel. Materials Science and Engineering A24 (1998) p.181-194.

[8] A. Alsaran, A. Celik, C. Celik.: Determination of the optimum conditions for ion nitriding of AISI 5140 steel. Surface and Coatings Technology V.160 (2002) p.219-226.

[9] S. S. Hosmani, R. E. Schacherl, and E. J. Mittemeijer: Morphology and Constitution of the Compound Layer Formed on Nitrided Fe-4wt.\% V Alloy. J. Mater. Sci., V.44 (2009) p.520-527.

[10] J. Qian, A. Fatemi: Cyclic deformation and fatigue behaviour of ion-nitrided steel. International Journal of Fatigue V. 17 (1995) p.5-24.

[11] M. Guagliano, L. Vergani: Effect of nitriding on low-cycle fatigue properties. International Journal of FatigueV. 19 (1997) p.67-73

[12] L. Yongshou, S. Xiaojun, L. Jun, Y. Zhufeng: Finite element method and experimental investigation on the residual stress fields and fatigue performance of cold expansion hole. Materials and Design V.31 (2010) p.1208-1215.

[13] M. ATerres, H. Sidhom: Fatigue Life Evaluation of 42CrMo4 Nitrided Steel by Local Approach: Equivalent Strain- Life Time. Material and Design, V.33 (2012) p.444-450

[14] T. Morita, H. Takahashi, M. shimizu, K. kawasaki: Factors controlling the fatigue strength of nitrided titanium. Fatigue Fract. Engng. Mater. Struct, V. 20 (1997) p.85-92.

[15] S. S. Hosmani, R. E. Schacherl, E. J. Mittemeijer: Nitrogen Absorption by $\mathrm{Fe}-1.04$ at.\% $\mathrm{Cr}$ Alloy: Uptake of Excess Nitrogen. J. Mater. Sci., V.43 (2008) p.2618-2624.

[16] M. A. Terres, H. Sidhom, H. P. Lieurade: Tenue en fatigue flexion d'un acier nitruré, (In French). Anales deChimie Sciences des Matériaux V.28 (2003) p.25-41.

[17] N. Ishikawa, T. Shiraga, K. Sato, M. Ishiguro, H. Kabasawa, Y. Kuwahara: Effects of Nitriding Temperature on Gas Nitriding Property of Steels for Nitriding. Journal of the iron and steel institute of Japan V.82 (1996) p.164-169.

[18] S. S. Hosmani, R. E. Schacherl, E. J. Mittemeijer: The Kinetics of the Nitriding of Fe-7Cr Alloys; The Role of the Nitriding Potential, Mater. Sci. Technol., V.21 (2005) p.113124.

[19] C. Kanchanomal, W. Limtrakan: Effect of Residual Stress on Fatigue Failure of Carbonitrited Low-Carbon Steel. Journal of Materials Engineering and Performance, V. 17 (2008) p.879887.

[20] A. Celik, S. Karadeniz: Investigation of compound layer formed during ion nitriding of AISI 4140. Surface and Coatings Technology V.80 (1996) p.283-286.

[21] M. Nikolussi, A. Leineweber, E. J. Mittemeijer: Nitrogen Diffusion through Cementite Layers. Philos. Mag., V.90 (2010) p.1105-1122. 